\title{
Study of $\Delta 9$-tetrahydrocannabinol (THC) and cannabidiol (CBD) extraction FROM dried oral fluid spots (DOFS) and LC-MS/MS detection
}

Roberta Gorziza', Joseph Cox², Renata Pereira Limberger ${ }^{1}$ and Luis E. Arroyo-Mora ${ }^{2^{*}}$

\begin{abstract}
Background: Oral fluid is a widely studied matrix able to isolate the primary Cannabis constituent THC, facilitating its detection via mass spectrometry, and in most cases link these findings to recent drug use. As an alternative to liquid oral fluid, dried oral fluid spots (DOFS) is a simple and a low-cost sampling technique. It has shown improved stability compared to liquid samples, allowing for the possibility to preserve the specimens under various temperature and humidity conditions. The sampling strategy is straightforward and involves the application of a small quantity of oral fluid aliquot to a paper substrate that is set to air dry allowing for on-site collection at a large-scale demand. The goal of this study is to study THC and CBD extraction from DOFS, applying a previous established protocol for a LC-MS/MS qualitative method validation. Although other drugs of abuse have been included in DOFS methods, this is the first method validation including cannabinoids. An alternative oral fluid extraction method (WAX-S tips) is demonstrated to improve the recovery of the analytes.
\end{abstract}

Methods: A pool of blank oral fluid was used to prepare THC and CBD spiked DOFS samples for method validation and application. Spiked oral fluid was used to demonstrate WAX-S tips THC and CBD extraction. All samples were analyzed on a LC-MS/MS instrument.

Results: The qualitative method validation for THC and CBD confirmation in DOFS included method selectivity, matrix effects (<20\%), recovery (average of 25\%), process efficiency (average of $21 \%), \mathrm{LOD}(2 \mathrm{ng} / \mathrm{mL}$ for THC and $4 \mathrm{ng} / \mathrm{mL}$ for CBD), absence of carryover, and DOFS stability (70\% in 35 days) as figures of merit. The method application in blindly prepared samples demonstrated the method capability to identify THC and CBD. WAX-S tips extraction showed an average of $91 \%$ recovery of THC and CBD from liquid oral fluid.

Conclusions: THC and CBD extraction from DOFS showed low recoveries. However, the LC-MS/MS qualitative confirmation of THC and CBD in DOFS could improve cannabinoids screening in oral fluid, as it shows adequate LOD and stability over time. This method has potential for assisting the screening of drivers under possible drug influence by facilitating sample transportation and temporary storage in dried spot form. Additional research is suggested for WAX-S tips extraction and quantitative method validation.

Keywords: Dried oral fluid spots, DOFS, Drug detection, THC, CBD, LC-MS/MS

*Correspondence: luis.arroyo@mail.wvu.edu

${ }^{2}$ Department of Forensic and Investigative Science, West Virginia University, 302 Oglebay Hall, Morgantown, WV 26506, USA

Full list of author information is available at the end of the article

\section{Background}

$\Delta$ 9-tetrahydrocannabinol (THC) is the main product of cannabis, known for its psychoactive effects, and cannabidiol (CBD) is the second major component of the plant (Russo and Guy 2006). CBD, combined with low THC concentrations, is associated with therapeutic effects 
(Russo and Guy 2006; Pisanti et al. 2017). Regulations for cannabis medical products vary among countries and states (Abuhasira et al. 2018) and there is a growing concern regarding the control of cannabis legal products, CBD based, which may contain higher THC levels than permitted (White 2019). Although the relation between cannabis medical use and driving safety is still limited, there are indications that its use has increased the prevalence of driving under the influence of cannabis (DUIC) (Fink et al. 2020).

Oral fluid is accepted as an adequate matrix for drug detection, offering valuable correlations with drug concentrations in blood (Cone and Huestis 2007). Oral fluid collection is not invasive as blood collection, and it can be performed by non-medical personnel, like police officers, therefore facilitating on-site collection (Drummer 2008; Walsh et al. 2008). In addition, the oral mucosa is exposed to high THC concentrations during smoking, the principal route of cannabis administration (Huestis 2007). For this reason, THC is the substance of choice to detect cannabis use in oral fluid. The European guideline Driving Under Influence of Drugs-DRUID (Schulze et al. 2012) recommended the value of $27 \mathrm{ng} /$ $\mathrm{mL}$ as cut-off for THC detection in oral fluid, while the North American agency Substance Abuse and Mental Health Services Administration (SAMHSA 2019) established lower cut-offs values $(4 \mathrm{ng} / \mathrm{mL}$ for screening tests and $2 \mathrm{ng} / \mathrm{mL}$ for confirmatory tests) for THC detection in oral fluid. Lower cut-offs are necessary considering that THC concentrations in oral fluid decrease fast with time, after smoking. A study, performed by Huestis and Cone (Huestis and Cone 2004), detected $5800 \mathrm{ng} / \mathrm{mL}$ of THC in oral fluid after $0.2 \mathrm{~h}$ of smoking; then, after $0.33 \mathrm{~h}$, the concentration decreased to $81 \mathrm{ng} / \mathrm{mL}$, reducing to less than $0.1 \mathrm{ng} / \mathrm{mL}$ after $12 \mathrm{~h}$. Similarly, Milman et al. (2012), detected $22,370 \mathrm{ng} / \mathrm{mL}$ of THC after $0.25 \mathrm{~h}$ of smoking, and after $6 \mathrm{~h}$ the concentrations decreased significantly $(0.9-90.4 \mathrm{ng} / \mathrm{mL})$, reducing to lower concentrations in $22 \mathrm{~h}(0.4-10.3 \mathrm{ng} / \mathrm{mL})$. Thus, THC identification in oral fluid is indicative of recent drug use due to its short detection times (Huestis 2007). The demonstration of recent drug use in oral fluid is valuable in particular situations, such as the screening for potential drivers under drug influence, the workplace testing, and anti-doping programs (Lee and Huestis 2014). This is not only to prevent accidents and prohibited use but also for post-accident or post-event evaluation of those involved in accidents (Lee and Huestis 2014).

Dried Matrix Spots (DMS) have been of interest in forensic toxicology (Chepyala et al. 2017; Sadler Simões et al. 2018; Caramelo et al. 2019; Ribeiro et al. 2019; Seymour et al. 2019; Gorziza et al. 2020), especially to simplify on-site sample collection while reducing time and resources. It consists of applying a small quantity of a biological sample (e.g., $50 \mu \mathrm{L}$ ) into a paper substrate, and set it to dry (Hannon and Therrell 2014; Resano et al. 2018). The simple approach facilitates sampling from collection sites located offsite from the actual laboratory where the analytical work is performed. This is particularly useful for DUIC screening. DMS are also designed for a simple and fast sample extraction, reducing resources cost and chemical waste (Déglon et al. 2015). When coupled to sensitive detection instruments, such as liquid chromatography tandem mass spectrometry (LC-MS/MS), it can provide drug detection at lower concentrations (Gorziza et al. 2020). THC identification and quantification have been shown in analytical methods using dried blood spots (DBS) (Thomas et al. 2012; Mercolini et al. 2013; Kyriakou et al. 2016; Protti et al. 2017), but THC isolation have been studied only for an extraction protocol using dried oral fluid spots (DOFS) (Stoykova et al. 2016).

Therefore, the aim of this study is to include THC and CBD detection to an established DOFS sampling protocol and an extraction procedure (Gorziza et al. 2020), which covered the identification and quantification of amphetamine, methamphetamine, benzoylecgonine, ketamine and mitragynine, using a LC-MS/MS instrument. To the best of our knowledge, CBD has been included for the first time in DMS, and it can help to evaluate cannabis medical use, among other scenarios. Additionally, disposable tips containing Weak Anion Exchange and Salt (WAX-S tips) were evaluated for the extraction of THC and CBD from oral fluid.

\section{Methods}

\section{Chemicals and materials}

THC, CBD, THC-d3 and CBD-d3 standards were acquired from Cerilliant (Round Rock, TX, USA). Methanol and acetonitrile-Optima ${ }^{\circledR}$ LC/MS Grade, ammonium formate and formic acid were purchased from Fisher Scientific (Waltham, MA, USA). Ultrapure water was obtained using a Direct-Q 3UV system of Millipore (Burlington, MA, USA). Whatman $903^{\circledR}$ paper was acquired from GE Healthcare Life Sciences (Marlborough, MA, USA) and WAX-S tips (300 $\mu$ L Hamilton $2 \mathrm{mg}$ WAX $+10 \mathrm{mg}$ salt) were purchased from DPX technologies (Columbia, SC, USA).

\section{Instrumentation}

The instrument for data acquisition was an Agilent Technologies Liquid Chromatography 1290 Infinity II coupled to an Agilent 6470 triple quadrupole MS/MS (Agilent Technologies, Santa Clara, CA), operated in positive electrospray ionization mode, ESI $(+)$.

Chromatographic separation of THC and CBD was obtained with a Zorbax RRHD C18 column $(3.0 \times 50 \mathrm{~mm}$, 
$1.8 \mu \mathrm{m}$ ) from Agilent (Santa Clara, CA, USA), using a gradient elution of $0.1 \%$ formic acid and $5 \mathrm{mM}$ ammonium formate in water (solvent $\mathrm{A}$ ), and acetonitrile with $0.1 \%$ formic acid (solvent B). The gradient was set with an initial flow of $95 \%$ solvent A for 0.5 min, reduced to $70 \%$ at $2 \mathrm{~min}$ and to $65 \%$ over $3 \mathrm{~min}$; then, at $4 \mathrm{~min}$, it was reduced to $50 \%$, and at $7 \mathrm{~min}$, it was reduced to $5 \%$, in a total run of $10 \mathrm{~min}$. The volume of injection was $1 \mu \mathrm{L}$.

Table 1 shows THC and CBD transitions established for the dynamic multiple reaction monitoring (dMRM) method, as well as their retention times. The monitored transitions were chosen using Agilent MassHunter Optimization software.

\section{DOFS preparation and extraction procedures}

DOFS sample preparation and extraction procedures were conducted as previously described (Jacques et al. 2019; Gorziza et al. 2020).

Blank oral fluid was obtained from laboratory staff volunteers. It was requested for them to not consume food and/or drinks at least one hour prior to the collection, which was performed by direct spitting into nonidentified polypropylene tubes. No personal information was requested, and all samples were pooled into a single container. The pooled oral fluid was kept at $6{ }^{\circ} \mathrm{C}$ for no longer than a week.

Previously cut pieces of Whatman $903^{\circledR}$ filter paper $(1,6 \mathrm{~cm} \times 1,6 \mathrm{~cm})$ were placed on a surface covered in aluminum foil, previously identified for each sample. Spots were spiked with $50 \mu \mathrm{L}$ of blank oral fluid and it was allowed to dry for at least $2.5 \mathrm{~h}$ at room temperature. Afterwards, the spots containing dried oral fluid were spiked with $50 \mu \mathrm{L}$ of a drug mix with THC and CBD, daily prepared at specific concentrations for validation procedures, and it were allowed to dry for at least $1.5 \mathrm{~h}$ at room temperature.

DOFS extraction was proceeded as it follows: a) the filter paper $(1.6 \mathrm{~cm} \times 1.6 \mathrm{~cm})$ was folded and transferred

\begin{tabular}{|c|c|c|c|c|}
\hline Drug & $\begin{array}{l}\text { Associated Internal } \\
\text { Standard (ISTD) }\end{array}$ & $m / z Q 1$ & $m / z Q 3$ & $\begin{array}{l}\text { Retention } \\
\text { Time } \\
\text { (Minutes) }\end{array}$ \\
\hline CBD & CBD-d3 & 315.2 & $\begin{array}{l}315.2 \rightarrow 123 \\
315.2 \rightarrow 193\end{array}$ & 8.22 \\
\hline THC & THC-d3 & 315.2 & $\begin{array}{l}315.2 \rightarrow 123 \\
315.2 \rightarrow 193\end{array}$ & 9.13 \\
\hline
\end{tabular}

to a polypropylene tube; b) $1 \mathrm{~mL}$ of extracting solvent (methanol: acetonitrile 50/50) was added; c) samples were submitted to $10 \mathrm{~min}$ of sonication; d) samples were submitted to $10 \mathrm{~min}$ of centrifugation, at $10,000 \mathrm{rpm}$; d) the supernatant was transferred to a glass vial and dried with a gentle nitrogen stream at $37{ }^{\circ} \mathrm{C}$ to prevent over drying; e) $100 \mu \mathrm{L}$ of reconstitution solution (95 $\mu \mathrm{L}$ of methanol and $5 \mu \mathrm{L}$ of an internal standard mix solution at the concentration of $1 \mu \mathrm{g} / \mathrm{mL}$ (final concentration of $50 \mathrm{ng} / \mathrm{mL}$ ) was added; f) samples were subjected to a vortex for $10 \mathrm{~s}$; g) $1 \mu \mathrm{L}$ of sample was injected in the LCMS/MS for analysis.

\section{WAX-S tips extraction}

Into a $1.5 \mathrm{~mL}$ polypropylene tube, $50 \mu \mathrm{L}$ of oral fluid spiked with THC and CBD (at the concentration of $12 \mathrm{ng} / \mathrm{mL}$ ), $100 \mu \mathrm{L}$ of acetonitrile and $5 \mu \mathrm{L}$ of an internal standard solution $(1 \mu \mathrm{g} / \mathrm{mL}$ solution of THC-d3 and CBD-d3, with a final concentration of $50 \mathrm{ng} / \mathrm{mL}$ ) were added. Using a $300 \mu \mathrm{L}$ WAX-S tip and a micropipette, the mix was aspirated and dispensed for three times. Then, $100 \mu \mathrm{L}$ of the top layer, a hydrophobic phase containing the analytes, was transferred to a glass vial and $1 \mu \mathrm{L}$ of sample was injected in the LC-MS/MS for analysis.

\section{Qualitative confirmation method validation}

The Standard Practices for Method Validation in Forensic Toxicology guideline (American Academy of Forensic Science (AAFS) Academy Standard Board (ASB). Standard Practices for Method Validation in Forensic Toxicology (2019)) established the required parameters for qualitative confirmation/identification methods: carryover, interference studies, ionization suppression/ enhancement, limit of detection and processed sample stability if applicable. Following these requirements, our qualitative method validation included carryover, selectivity and interference studies, ionization suppression/ enhancement (matrix effects) limit of detection (LOD), and stability as figures of merit. Additionally, extraction recovery and process efficiency were also evaluated.

Selectivity and interferences were evaluated using three different approaches. Initially, THC, CDB and their respective internal standards were injected individually. Considering that the optimized transitions for CBD and for THC were the same, these compounds were differentiated by their retention times in chromatography (8.22 and $9.13 \mathrm{~min}$, respectively). The second approach evaluated a pool of blank oral fluid from ten different volunteers, in triplicates, with and without internal standards. THC and CBD's absence were then checked on these samples. Finally, common compounds (Table 2) 
Table 2 List of compounds (methanolic standards) evaluated for possible interferences in the liquid chromatography tandem mass spectrometry (LC-MS/MS) method for $\triangle 9$-tetrahydrocannabinol (THC) and cannabidiol (CBD) identification

\begin{tabular}{ll}
\hline Class & Compounds \\
\hline Opioids & 6-Acetylmorphine \\
& Oxycodone \\
& Hydrocodone \\
& Buprenorphine \\
& Norbuprenorphine \\
& Ethylmorphine \\
& JWH-018 \\
& JWH-073 \\
& XLR-11 \\
Synthetic cannabinoids & AB-FUBINACA \\
& AB-PINACA \\
& MAM2201 \\
& Amphetamine \\
& Methamphetamine \\
& Cocaine \\
Stimulants & Ketamine \\
& Mitragynine \\
1S,2R (+)- Ephedrine & Methylphenidate \\
Dissociative Anesthetic & Sibutramine \\
Other alkaloids & Caffeine \\
Supplements & Synephrine \\
& Octopamine \\
& Methylhexanamine (DMAA) \\
&
\end{tabular}

were subjected to the method to check for possible interferences.

Matrix effects, extraction recovery and process efficiency were evaluated as previously described by Matuszewski et al. (2003). For these experiments, DOFS samples were prepared as described in section DOFS Preparation and Extraction Procedures, using a pool of blank oral fluid from seven different volunteers. Three sets of samples were prepared at administratively determined low and high concentrations $(12 \mathrm{ng} / \mathrm{mL}$ and $50 \mathrm{ng} / \mathrm{mL}$, respectively): a) 6 replicates of neat standard solutions in methanol; b) 10 replicates of DOFS samples fortified after extraction; c) 10 replicates of pre-spiked DOFS samples. Afterwards, the mean peak areas for each set were used to calculate matrix effects (ME), process efficiency (PE) and recovery (RE) percentages, according to the formulas:

$$
\operatorname{ME}:\left(\frac{b}{a}\right) \times 100 P E:\left(\frac{c}{a}\right) \times 100 R E:\left(\frac{c}{b}\right) \times 100
$$

WAX-S tips were also studied for THC and CBD extraction from oral fluid. For these experiments, samples were prepared using a pool of blank oral fluid obtained from seven different volunteers. In this matter, ME, PE and RE were calculated, as previously described above, using a) 6 neat standards solutions in methanol, b) 10 post-spiked samples, and c) 10 pre-spiked samples. As a demonstration, WAX-S tips were evaluated only for a low concentration $(12 \mathrm{ng} / \mathrm{mL})$.

The LOD was determined by fortifying DOFS samples (prepared with a pool of blank oral fluid from seven different volunteers), at decreasing concentrations (4, 2, 1 and $0.2 \mathrm{ng} / \mathrm{mL}$ ) for at least three runs. LOD was defined as the lowest concentration at which the signalto-noise $(\mathrm{S} / \mathrm{N})$ ratio was equal or greater than 3.3, and it could be also visually determined from chromatographic peaks analysis and THC and CBD monitored transitions (Table 1).

Carryover was assessed by injecting three blank matrix samples (prepared with a pool of blank oral fluid from seven different volunteers), after extracted DOFS samples containing $100 \mathrm{ng} / \mathrm{mL}$ of THC and of CBD. It was considered insignificant if the LOD criteria were not met.

Finally, a triplicate of DOFS samples (prepared with a pool of blank oral fluid from seven different volunteers) was prepared, spiked at a medium concentration of $30 \mathrm{ng} / \mathrm{mL}$, and dried overnight, therefore kept in a plastic bag at $6{ }^{\circ} \mathrm{C}$. After 35 days, these samples were extracted as previously described in section DOFS Preparation and Extraction Procedures, and compared to freshly prepared and extracted DOFS samples, to evaluate DOFS stability.

\section{Method application}

As authentic samples were not available to evaluate the validated method, a blind study with simulated DOFS samples $(n=8)$ was conducted. A pool of blank oral fluid $(\mathrm{n}=7)$ was applied on the filter papers $(50 \mu \mathrm{L})$, it was allowed to dry $(2.5 \mathrm{~h})$ and therefore it was spiked with different THC and/or CBD concentrations, higher than their LODs (2 and $4 \mathrm{ng} / \mathrm{mL}$, respectively). A researcher, different from the one that proceeded with the sample extractions and analysis, prepared eight different drug mixes to spike the DOFS samples $(50 \mu \mathrm{L})$. After drying $(1.5 \mathrm{~h})$, the spiked DOFS samples were extracted as previously described. After sample extraction and analysis, the eight samples were evaluated by the researcher as "positive" or "negative" for THC and for CBD, and further compared to the blindly prepared drug mixes. 


\section{Results}

\section{Chromatography}

Initially, the chromatographic separation for the isolation of THC and CBD was evaluated. The method has presented proper selectivity for THC and CBD. Both analytes were identified by the same transitions (Table 1), therefore their elution should occur at different retention times in chromatography. Figure 1 shows CBD eluted at $8.22 \mathrm{~min}$ and $\mathrm{THC}$ at $9.13 \mathrm{~min}$. The chromatographic separation allowed for adequate $\mathrm{CBD}$ and THC visual discrimination.

\section{Sample preparation}

The first step for DOFS sample preparation is to define the adequate filter paper, its size, its capability of oral fluid absorption and the amount of time needed for complete dryness. Jacques et al. (2019) studied these conditions for Whatman $9033^{\circledR}$ filter paper, defining that a $1.6 \mathrm{~cm} \times 1.6 \mathrm{~cm}$ piece of paper would be necessary to absorb $50 \mu \mathrm{L}$ of oral fluid. This sample require a minimum of $2.5 \mathrm{~h}$ to dry. Our protocol utilized this study as a reference for these sample preparation parameters.

The second aspect of DOFS sample preparation is oral fluid collection. To simplify and to reduce the costs for this procedure, the collection was performed by direct spitting of neat oral fluid into polypropylene tubes. Neat oral fluid is a viscous sample, and it is an intrinsic factor in authentic samples. However, it is an aspect of concern in method validation. Gorziza et al. (2020) discuss how previous DOFS studies handle drug spiking in oral fluid, reporting the use of artificial, frozen or centrifugated oral fluid. These procedures do not represent the practical scenario for sample collection. Therefore, based on Numako et al. (2016) study, Gorziza et al. (2020) propose a two-step DOFS sample preparation, by adding total oral fluid on the filter paper and, after drying, adding the methanolic mix of drugs. The two-step process is necessary to respect the filter paper absorption capability of only $50 \mu \mathrm{L}$ at a time. This procedure utilizes authentic oral fluid, and it guarantees the drug quantities for method validation, avoiding dilution in viscous samples. Thus, our sample preparation followed Gorziza et al. (2020) two-step protocol.

DOFS sample extraction was also performed as previously described for other five drugs of abuse (Gorziza et al., 2020). However, extraction using methanol as solvent and glass materials were also tested, following previous studies with DBS (Mercolini et al. 2013; Kyriakou et al. 2016; Protti et al. 2017). These modifications did not perform better than the initial protocol.

WAX-S tips are disposable tips containing weak anion exchange (WAX) sorbent and salt (S), allowing for a salting-out assisted liquid-liquid extraction (SALLE). Although WAX tips are recommended for strong and weak acids analysis (DPX Technologies), when combined with salt for SALLE, WAX-S tips are recommended for

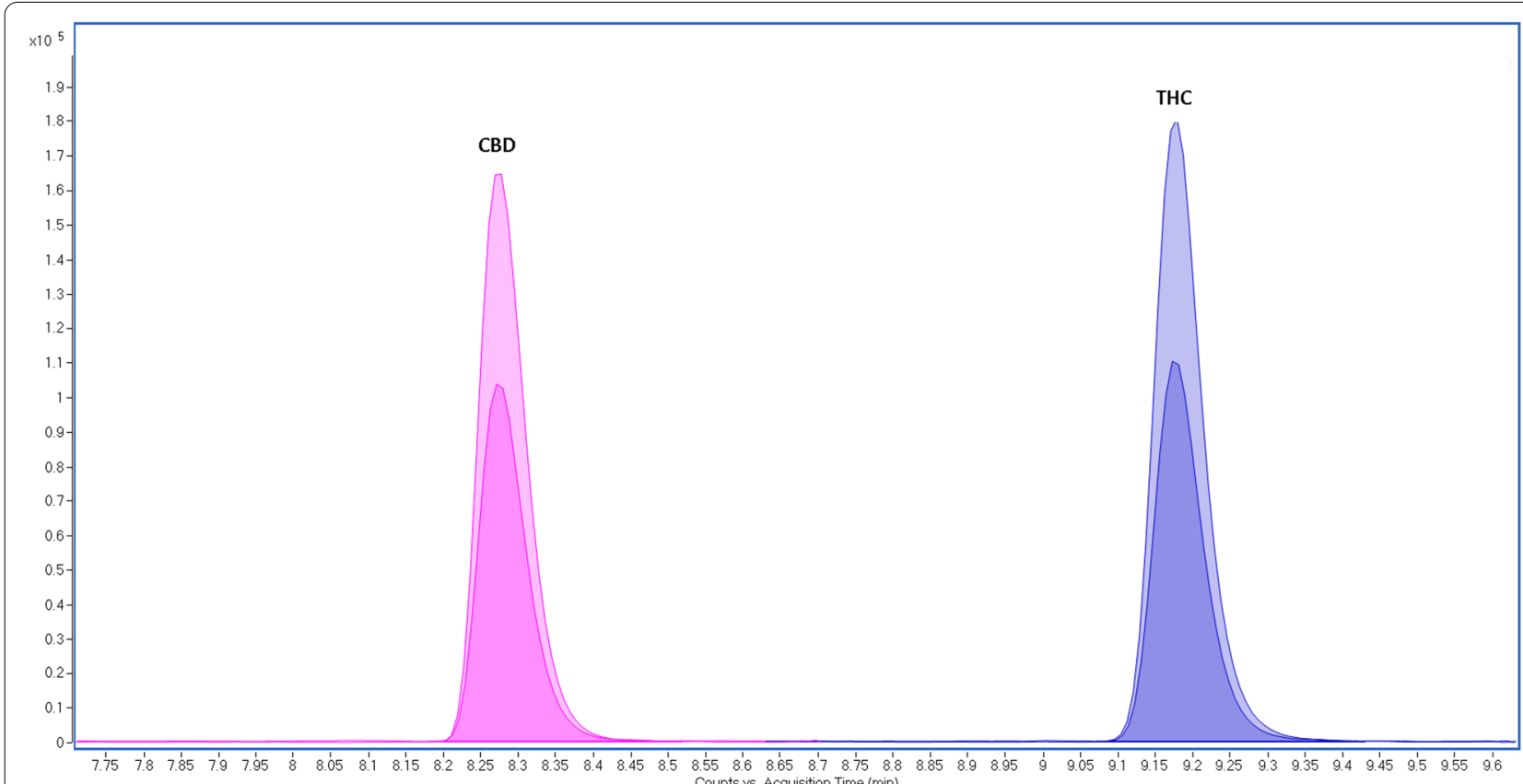

Fig. 1 CBD and THC chromatographic separation at 8.22 and 9.13 min, respectively. The chromatogram was extracted from an injection of a methanolic solution at $25 \mathrm{ng} / \mathrm{mL}$ 
hydrophobic compounds, such as cannabinoids (DPX Technologies). The sample preparation includes the pretreatment with acetonitrile, for protein precipitation. It was added $100 \mu \mathrm{L}$ of acetonitrile to $50 \mu \mathrm{L}$ of spiked oral fluid. The extraction involves the steps of conditioning, mixing the sample with the loose sorbent inside the tip, followed by activation, with the analytes binding to the sorbent, and the washing of matrix interferences. Finally, the analytes of interest are eluted in acetonitrile (DPX Technologies). The extraction and the elution steps occur by aspirating/dispensing all $150 \mu \mathrm{L}$ of liquid for three times. This method has been successfully applied for cannabinoids extraction from blood (Scheidweiler et al. 2016) and from urine (Andersson et al. 2016); the reported cannabinoid recoveries are between 54-84.4\% and $42.4-81.5 \%$, respectively. Therefore, it demonstrated satisfactory results in our study with oral fluid.

\section{Qualitative confirmation method}

The tests for selectivity showed that the LC-MS/MS method was capable to properly identify THC and CBD. No interferences from endogenous peaks or signal contribution from internal standards were observed. In addition, different compounds with potential to be found in oral fluid (opioids, synthetic cannabinoids, stimulants, supplements, a dissociative anesthetic and an alkaloid Table 2) were subjected to the method, and no interfering peaks for THC and CBD were observed.

After the establishment for the detection method, matrix effects, extraction recovery, process efficiency,
LOD, carryover, and DOFS stability were evaluated as figures of merit for the qualitative method validation.

Matrix effects, recovery and process efficiency were studied for DOFS samples and subsequently for the WAX-S tips extraction method. All the results are shown in Table 3. Ion suppression was observed for THC and for CBD using both methods (DOFS and WAX-S tips), but these values are lower than $25 \%$. The analyte's average recovery was $25 \%$ and $91 \%$ for DOFS and WAX-S tips methods, respectively, along with an average process efficiency of $21 \%$ and $82 \%$ for DOFS and WAX-S tips methods, respectively.

The next parameter evaluated for the DOFS method validation was the LOD, which was defined after analyzing six replicates at $0.2,1,2$ and $4 \mathrm{ng} / \mathrm{mL}$, for THC and for CBD. For THC the LOD was established at $2 \mathrm{ng} / \mathrm{mL}$ and, for CBD, it was established at $4 \mathrm{ng} / \mathrm{mL}$. These concentrations showed signal-to-noise $(\mathrm{S} / \mathrm{N})$ values higher than 3.3, as well as their peak bases could be visually determined by the analyzer. After defining the LODs values, carryover was assessed by injecting blank oral fluid samples $(n=3)$ immediately after a high concentration of THC and of CBD (100 ng/mL). No carryover was observed, considering that the LOD criteria were not met by the blank oral fluid samples. Finally, DOFS stability was evaluated for a 35 days period. DOFS samples (at a concentration of $30 \mathrm{ng} / \mathrm{mL}$ ) were kept at $6{ }^{\circ} \mathrm{C}$ and then extracted and compared to freshly prepared DOFS samples. Considering this period, a $30 \%$ loss was observed for $\mathrm{THC}$ and CBD.

Table 3 Matrix effects, absolute recovery and process efficiency for $\triangle 9$-tetrahydrocannabinol (THC) and cannabidiol (CBD), using dried oral fluid spots (DOFS) and weak anion exchange and salt (WAX-S) tips extraction

\begin{tabular}{|c|c|c|c|c|c|c|}
\hline Drug & $\begin{array}{l}\text { Matrix Effects* } \\
(\%)\end{array}$ & $\begin{array}{l}\mathrm{CV} \\
(\%)\end{array}$ & $\begin{array}{l}\text { Absolute Recovery* } \\
\text { (\%) }\end{array}$ & CV & $\begin{array}{l}\text { Process Efficiency * } \\
\text { (\%) }\end{array}$ & $\begin{array}{l}\text { CV } \\
(\%)\end{array}$ \\
\hline \multicolumn{7}{|l|}{ THC $(\mathrm{N}=10)$} \\
\hline \multicolumn{7}{|l|}{ DOFS } \\
\hline Low (12 ng/mL) & 98.7 & 15.6 & 23.8 & 14.2 & 23.5 & 19.3 \\
\hline High (50 ng/mL) & 80.3 & 17.3 & 25.3 & 13.9 & 20.3 & 20.7 \\
\hline \multicolumn{7}{|l|}{ WAX-S tips } \\
\hline Low (12 ng/mL) & 92.4 & 6.8 & 90.7 & 6.2 & 83.8 & 4.0 \\
\hline \multicolumn{7}{|l|}{$\mathrm{CBD}(\mathrm{N}=10)$} \\
\hline \multicolumn{7}{|l|}{ DOFS } \\
\hline Low (12 ng/mL) & 75.2 & 18.5 & 24.8 & 18.0 & 18.6 & 23.9 \\
\hline High (50 ng/mL) & 76.4 & 18.7 & 28.7 & 17.6 & 21.9 & 23.8 \\
\hline \multicolumn{7}{|l|}{ WAX-S tips } \\
\hline Low (12 ng/mL) & 87.5 & 7.0 & 93.2 & 8.7 & 81.6 & 5.5 \\
\hline
\end{tabular}

* Matrix effects: accessed by dividing post-spiked average and neat samples, multiplied by 100;

* Process efficiency: accessed by dividing pre-spiked samples by neat samples, multiplied by 100 ;

* Recovery: calculated dividing pre-spiked samples by post-spiked samples, multiplied by 100 


\section{Method application}

Once the method validation was complete, a blind study with DOFS spiked samples was conducted to evaluate its fits of purpose. Eight simulated samples were prepared and analyzed for THC and for CBD identification. The target analytes were correctly identified and confirmed in all samples: three samples were positive for THC; three different samples were positive for CBD and two samples were negative for both compounds.

\section{Discussion}

A complete qualitative confirmation method is presented for THC and CBD identification in DOFS samples, coupled to a LC-MS/MS method. Additionally, a blind study with simulated samples was conducted as a proof of the method capability.

DOFS sampling and extraction has been successfully demonstrated in validated quantitative methods for different drugs of abuse and/or its metabolites detection: amphetamine, methamphetamine, 3,4-methylenedioxymethamphetamine (MDMA), cocaine, benzoylecgonine, cocaethylene, ketamine, mitragynine, methadone and 2-ethylidene-1,5-dimethyl-3,3-diphenylpyrrolidine (EDDP) (Jacques et al. 2019; Ribeiro et al. 2019; Gorziza et al. 2020). DOFS is an easy and practical sampling technique, however drug extraction from the filter paper is also an analytical challenge. Compound recovery will depend on a proper sample extraction protocol, as well as on each analyte affinity with the filter paper. For example, in a single DOFS extraction protocol the average recovery for amphetamine, methamphetamine, ketamine and benzoylecgonine was $82 \%$, while the average recovery for mitragynine was only 55\% (Gorziza et al. 2020). Similarly, Ribeiro et al. (2019) have obtained $67 \%$ of average recovery for methadone, and 54\% for EDDP. Both mitragynine and methadone are lipophilic drugs (Gallagher 2009; Ramanathan et al. 2015), which could be one of the reasons for a higher interaction with the filter paper, leading to poor recoveries ratios $(<70 \%)$.

Cannabinoids are highly lipophilic drugs (Huestis 2007) and its adsorption onto plastic containers (Molnar et al. 2013) have been linked to poor cannabinoids recovery and stability in oral fluid, depending on the materials and/or buffers of sample collection devices (Lee and Huestis 2014). The extraction of THC and CBD from DOFS samples have shown limitations as well. After experimentally applying a successful extraction protocol of other drugs of abuse from DOFS (Gorziza et al. 2020) to include THC and CBD extraction, it was found a $25 \%$ average recovery for these compounds, along with a $21 \%$ average of process efficiency (Table 3 ). Both recovery and process efficiency are calculated from pre-spiked samples peak areas, divided by post-spiked samples and by neat samples peak areas, respectively (Matuszewski et al. 2003). While recovery considered the oral fluid effect, process efficiency compared DOFS samples extraction to accurate concentrations of drugs in methanol, so it is expected to observe similar, but lower values for process efficiency. The difference between these parameters represents the matrix effects, which showed an average value of $16 \%$ of ion suppression in DOFS (Table 3), and it is an acceptable value.

Stoykova et al. (2016) has studied THC extraction from DOFS for the first time. In this study, THC along with amphetamine, methamphetamine, 3,4-methylenedioxymethamphetamine, cocaine, morphine, methadone, and clonazepam was spiked in oral fluid and therefore spotted onto a non-specified filter paper for drying. The extraction of these drugs from the filter paper using ethyl acetate and $1 \mathrm{M}$ sodium hydroxide as an extraction solvent have shown $>70 \%$ recovery for all compounds, except for THC and clonazepam. For this reason, an extra DOFS pre-treatment (with methanol and $0.1 \mathrm{M}$ hydrochloric acid) was added to achieve a $45 \%$ THC recovery, which is still a low percent value.

THC recovery from filter papers has also been studied using blood as a matrix (DBS). In 2012, Thomas et al. (2012) presented an extraction protocol from dried blood in a TNF Sartorius Card paper. This protocol utilizes a mixture of methanol and tert-butyl-methylether solvents as a first extraction solution, followed by 45 min sonication and a final step of centrifugation for $5 \mathrm{~min}$. Afterward, a second extraction with acetone was performed including another $30 \mathrm{~min}$ of sonication. Besides using this extensive extraction protocol, only a $19 \%$ recovery from the dried blood on filter paper was reported, a figure even lower than the one we have found in our DOFS protocol (25\%). However, in the following years, three different studies reported recoveries $>80 \%$ THC when using DBS (Mercolini et al. 2013; Kyriakou et al. 2016; Chepyala et al. 2017). The extraction protocol followed by these research groups are described on Table 4. Attempting to improve THC and CBD recoveries obtained from our DOFS extraction protocol, we have evaluated these previously studied protocols, analyzing which filter paper types and extraction solutions they have utilized, as well as their extraction procedures details (e.g. tube material, vortexing, centrifugation, sonication, solvent evaporation).

While working with dried spots it is essential to choose an appropriate filter paper to avoid inter-samples variation, and to optimize an extraction solvent to elute each target analyte from the paper, as well as time of extraction, and sonication (Zakaria et al. 2016). In the four previous studies with THC on DBS, three different types of filter paper were chosen, including Whatman $903^{\circledR}$, the 
Table 4 Comparative $\triangle 9$-tetrahydrocannabinol (THC) extraction protocols from dried blood spots, of previous studies

\begin{tabular}{|c|c|c|c|c|}
\hline Reference & Thomas et al. (2012) & Mercolini et al. (2013) & Kyriakou et al. (2016) & Protti et al. (2017) \\
\hline Paper Type & $\begin{array}{l}\text { Sartorius TNF } \\
\text { Card }^{\circledR}\end{array}$ & Whatman $903^{\circledR}$ & Whatman $903^{\circledR}$ & $\begin{array}{l}\text { Whatman FTA }{ }^{\mathrm{TM}} \\
\text { DMPK-C Card }{ }^{\circledR}\end{array}$ \\
\hline Extraction Solution & $\begin{array}{l}\text { Step 1. } 100 \mu \mathrm{L} \text { of } \mathrm{MeOH}^{\mathrm{a}}+400 \mu \mathrm{L} \\
\text { of TBME } \\
\text { Step 2. } 300 \mu \mathrm{L} \text { of acetone }\end{array}$ & $1 \mathrm{~mL}$ of $\mathrm{MeOH}^{\mathrm{a}}$ & $990 \mu \mathrm{L}$ of $\mathrm{MeOH}^{\mathrm{a}}$ and $10 \mu \mathrm{L}$ of $\mathrm{IS}^{\mathrm{b}}$ & $1 \mathrm{~mL}$ of $\mathrm{MeOH}^{\mathrm{a}}$ \\
\hline Tube & Polypropylene & Vial & Not informed & Vial \\
\hline Procedures & $\begin{array}{l}\text { Step } 1.45 \text { min of sonication } \\
\text { and } 5 \text { min of centrifugation } \\
(13,000 \times \mathrm{g}) \\
\text { Step } 2.30 \text { min of sonication }\end{array}$ & $\begin{array}{l}1 \mathrm{~min} \text { of vortexing and } 5 \mathrm{~min} \\
\text { of centrifugation }(1400 \times \mathrm{g})\end{array}$ & $\begin{array}{l}15 \text { min of sonication and } 5 \text { min } \\
\text { of centrifugation }(3500 \times \mathrm{g})\end{array}$ & $\begin{array}{l}1 \text { min of vortexing and } \\
5 \text { min of centrifuga- } \\
\text { tion (4000 rpm) }\end{array}$ \\
\hline Solvent Evaporation & Vacuum centrifuge, $40^{\circ} \mathrm{C}$ & Vacuum & Vacuum & $\begin{array}{l}\text { Nitrogen } \\
\text { Stream }\end{array}$ \\
\hline Extraction Recovery & $19 \%$ & $83 \%$ & $81 \%$ & $92 \%$ \\
\hline
\end{tabular}

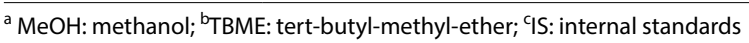

one utilized in our DOFS study. After guaranteeing the filter paper quality to spot samples and allowing them to dry, analytes recoveries depend on standardizing an adequate elution from the paper and on minimizing the compounds losses and/or degradation through the procedure (Zakaria et al. 2016). In regards to extraction efficiency, the studies that present higher THC percent recoveries (Mercolini et al. 2013; Kyriakou et al. 2016; Protti et al. 2017) reported the use of pure methanol as extraction solvent, also using a short period of time (5 min) of centrifugation for THC extraction (Table 4). Of these studies, only Kyriakou et al. (2016) added a sonication step (15 $\mathrm{min}$ ) to their protocol which was also applied to our DOFS extraction protocol to improve the analyte elution. We have experimentally tested the use of pure methanol in our DOFS protocol, applying 10 min of sonication following $10 \mathrm{~min}$ of centrifugation, and it did not perform better than a mixture of methanol and acetonitrile $(50 / 50, \mathrm{v} / \mathrm{v})$, initially utilized in our protocol, for THC or for CBD extraction. The mixture was then chosen considering that THC and CBD detection could be added into a protocol for concomitant detection of a major pool of drugs of abuse, as previously described (Gorziza et al. 2020). As for inherent factors through the extraction procedure, previous studies have observed THC and CBD loss to plastic containers during the experiments (Molnar et al. 2013). In this matter, it was noticed that Mercolini et al. (2013) and Protti et al. (2017) describe their experiments using a glass vial (Table 4), and then we conducted an experiment for DOFS extraction avoiding all kinds of plastic, including tubes and pipette tips. However, THC and $\mathrm{CBD}$ recoveries remained the same $(25 \%$ and $26 \%$, respectively). A second hypothesis for THC and CBD loss would be their degradation over the process of solvent drying using a nitrogen stream. Nonetheless, while
Mercolini et al. (2013) and Kyriakou et al. (2016) used a vacuum system for solvent drying, Protti et al. (2017) utilized a nitrogen stream (Table 4), like it was used in our DOFS extraction protocol. Therefore, our experiments suggest that the major loss for THC and CBD on DOFS have occurred by affinity with the filter paper. Although Mercolini et al. (2013) and Kyriakou et al. (2016) have reported $>80 \%$ recoveries for THC from DBS in Whatman $903^{\circledR}$ filter papers, these results were not reproducible using our DOFS extraction protocol. Our findings corroborate Stoykova et al. (2016) previous results for THC extraction using DOFS and Thomas et al. (2012) findings for THC extraction from DBS.

These limitations for THC and CBD recoveries from the filter paper have impacted on the LOD definition for our method. The LC-MS/MS instrument would be capable of detecting THC concentrations as low as $0.5 \mathrm{ng} / \mathrm{mL}$, experimentally tested. However, to achieve this concentration after DOFS extraction with $25 \%$ recovery, a minimum THC concentration of $2 \mathrm{ng} / \mathrm{mL}$ in oral fluid (the established LOD for THC) is necessary. For CBD, the LOD was established at $4 \mathrm{ng} / \mathrm{mL}$. Moreover, the recovery issues have impaired a quantitative analysis method validation. SAMHSA (SAMHSA 2019) have published a Mandatory Guideline for Federal Workplace Drug Testing Programs, for oral fluid samples, recommending a minimum of $80 \%$ recovery for THC from oral fluid collection devices, for confirmatory methods. Using this guideline as a parameter, the THC recovery percent from DOFS (25\%) does not fit this requirement.

However, besides these limitations, the DOFS sampling method still provide advantages as a qualitative method for CBD and for THC identification and screening. For instance, drugs of abuse screening methods - using liquid chromatography and mass spectrometry-have been 
proposed for dried spots sampling using blood (Ambach et al. 2014; Chepyala et al. 2017) and urine (Michely et al. 2017; Pablo et al. 2020) as biological matrices. Studies in blood did not included cannabinoids in their panel of drugs, and, in urine, the metabolite 11-nor-9-Carboxy$\triangle 9$-THC (THC-COOH) has been included with a LOD of $50 \mathrm{ng} / \mathrm{mL}$ (Pablo et al., 2020). Therefore, oral fluid presents advantages in demonstrating recent drug abuse.

Our DOFS qualitative method has demonstrated a low LOD for THC (2 $\mathrm{ng} / \mathrm{mL})$, which fits SAMHSA cut-off criteria recommendation for screening tests $(4 \mathrm{ng} / \mathrm{mL})$ in oral fluid (SAMHSA 2019). In addition, the qualitative confirmation analysis for THC and CBD on DOFS can occur concomitantly with the quantitative analysis for other drugs of abuse (Gorziza et al. 2020), in a single extraction method and detection instrument. Thus, when analyzing immunochromatographic screening tests, often used for roadside drug detection, there is a great variability, particularly for THC, concerning its cutoffs values, sensibility, specificity and accuracy, between different devices brands (Dobri et al. 2019). Therefore, insufficient oral fluid volume, device usability (e.g. testing time, failed tests and test reading) and instability due to cold weather have been reported as limitations of immunochromatographic screening tests for THC (Dobri et al. 2019). Comparatively, DOFS qualitative method provides THC and CBD precise identification with adequate sensitivity, fitting guidelines recommendations for LOD. In addition, considering its demonstrable stability (70\% in 35 days, for both THC and CBD compounds), DOFS sampling is a suitable alternative for situations that require long distances sample collection and transportation, such as the roadside screening for suspected drivers under drug influence. Thus, DOFS is a low-cost procedure, requiring only a common polypropylene tube, a pipette tip and the filter paper, and it can be an alternative for a large demand of samples. The liquid-liquid extraction for DOFS also presents a lower cost than using a SPE cartridge, therefore saving time and reagents (solvents, nitrogen gas and chemical waste) in the extraction protocol for oral fluid.

To overcome the recovery limitation that we have observed in DOFS extraction for THC and for CBD, we have studied a new extraction method with WAX-S tips, as a suggestion for an alternative quantitative analysis. The WAX-S tips method utilizes liquid oral fluid, but it requires a low sample volume $(50 \mu \mathrm{L})$, like DOFS. This advantage would allow for concomitant analysis between DOFS and WAX-S tips: the use of DOFS for THC and CBD sensitive screening, followed by WAX-S tips quantitative analysis if necessary.

WAX-S tips are disposable cartridges, similar to SPE techniques, but coupled to a micropipette. These tips contain a packed solid-phase sorbent in which the mixture of oral fluid and acetonitrile interact with during sample extraction through liquid aspiration and dispensing. Like DOFS, this method requires small amount of solvents $(100 \mu \mathrm{L})$. In addition, the extraction procedure demands only a short period of time and dispenses the need of solvent evaporation, therefore reducing costs. The WAX-S tips method improved drug recoveries in oral fluid (Gorziza et al. 2020). In our study with THC and CBD detection in oral fluid, WAX-S tips also increased the drug recovery average, from $25 \%$ in DOFS to a $90 \%$, with an average of $82 \%$ of process efficiency (Table 3). However, it must be noted that this study was performed with freshly spiked oral fluid, immediately extracted. In practical routine testing such as DUIC cases, oral fluid will be collected and transported to the laboratory for analysis. Oral fluid collection can be proceeded by direct spitting into a tube (like it was conducted in this study) or using a collection device constituted of a swab pad that conducts the oral fluid into a tube containing buffer and preservatives. While a collection device simplifies the procedure while helping with oral fluid viscosity and drug recoveries in general, increased absorptivity to collection devices is observed for lipophilic drugs, like THC (Crouch 2005). For instance, Langel et al. (2008) evaluated 9 different devices for oral fluid collection and drug recoveries, and substantial differences were found between the devices, especially for THC. In conclusion, WAX-S tips extraction is a fast and promising extraction method for cannabinoids in oral fluid should be further studied for a quantitative analysis combined with adequate oral fluid collection, following the identification of THC and CBD in DOFS.

\section{Conclusions}

Oral fluid is a valuable matrix to detect cannabis recent use, effective in situations such as the screening of DUIC cases. Although THC and CBD compounds have been extensively studied in oral fluid, this is the first time that these compounds were studied for an analytical method validation in DOFS to ensure its applicability. Dried spots are a low-cost sampling method, which has demonstrated improved stability when compared to liquid samples. This advantage facilitates on-site collection and sample transportation, particularly required for long distances collections such as DUIC cases. A complete qualitative method validation is presented for THC and CBD confirmation in DOFS. As recovery issues have impaired a quantitative method validation in this study, which corroborates previous findings for THC in dried matrices, an alternative extraction method (WAX-S tips) 
is demonstrated to improve THC and CBD recoveries, and therefore it is suggested for further complementary quantitative studies.

\author{
Abbreviations \\ THC: $\triangle 9$-Tetrahydrocannabinol; CBD: Cannabidiol; DMS: Dried matrix spots; \\ DOFS: Dried oral fluid spots; DBS: Dried blood spots; WAX-S: Weak Anion \\ Exchange and Salt; DUIC: Driving under the influence of cannabis; DRUID: \\ Driving under the influence of drugs; SAMHSA: Substance Abuse and Mental \\ Health Services Administration.
}

\section{Acknowledgements}

The authors wish to thank Coordenação de Aperfeiçoamento de Pessoal de Nível Superior (CAPES) and Conselho Nacional de Desenvolvimento Científico e Tecnológico (CNPq) Brazilian Institutions for support.

\section{Authors' contributions}

RG conducted the experiments and wrote the first draft of this article. JC provided technical and scientifical assistance, results interpretation, as well as text editing. RPL conceived and reviewed the study, also assisting with results interpretation and text editing. LEAM contributed with scientifical assistance, results interpretation and major text editing. The author(s) read and approved the final manuscript.

\section{Funding}

This study is part of a Forensic Sciences Project, approved by the Brazilian Institution CAPES, under number 25/2014-"PRO-FORENSES 3357/2014", Process $n^{\circ} 23038.006845 / 2014-91$. This project funded RG during the split PhD program at West Virginia University.

\section{Availability of data and materials}

The data analyzed in this study are available from the corresponding author on reasonable request.

\section{Declarations}

\section{Ethics approval and consent to participate}

Not applicable.

\section{Consent for publication}

Not applicable.

\section{Competing interests}

The authors declare that they have no competing interests.

\section{Author details}

${ }^{1}$ Department of Pharmacy, Federal University of Rio Grande Do Sul, Av. I piranga 2752, Porto Alegre, RS 90610-000, Brazil. ${ }^{2}$ Department of Forensic and Investigative Science, West Virginia University, 302 Oglebay Hall, Morgantown, WV 26506, USA.

Received: 30 September 2020 Accepted: 5 July 2021

Published online: 12 July 2021

\section{References}

Abuhasira R, Shbiro L, Landschaft Y. Medical use of cannabis and cannabinoids containing products - Regulations in Europe and North America. Eur J Intern Med. 2018;49:2-6. https://doi.org/10.1016/j.ejim.2018.01.001.

Ambach L, Hernández Redondo A, König S, Weinmann W. Rapid and simple LC-MS/MS screening of 64 novel psychoactive substances using dried blood spots. Drug Test Anal. 2014;6:367-75. https://doi.org/10.1002/dta. 1505.

American Academy of Forensic Science (AAFS) Academy Standard Board (ASB). Standard Practices for Method Validation in Forensic Toxicology. Am Acad Forensic Sci. 2019.
Andersson M, Scheidweiler KB, Sempio C, et al. Simultaneous quantification of 11 cannabinoids and metabolites in human urine by liquid chromatography tandem mass spectrometry using WAX-S tips. Anal Bioanal Chem. 2016;408:6461-71. https://doi.org/10.1007/s00216-016-9765-8.

Caramelo D, Rosado T, Oliveira V, et al. Determination of antipsychotic drugs in oral fluid using dried saliva spots by gas chromatography-tandem mass spectrometry. Anal Bioanal Chem. 2019;411:6141-53. https://doi.org/10. 1007/s00216-019-02005-8.

Chepyala D, Tsai IL, Liao HW, et al. Sensitive screening of abused drugs in dried blood samples using ultra-high-performance liquid chromatography-ion booster-quadrupole time-of-flight mass spectrometry. J Chromatogr A. 2017;1491:57-66. https://doi.org/10.1016/j.chroma.2017.02.037.

Cone EJ, Huestis MA. Interpretation of oral fluid tests for drugs of abuse. In: Annals of the New York Academy of Sciences. Blackwell Publishing Inc. 2007 51-103

Crouch DJ. Oral fluid collection: The neglected variable in oral fluid testing. Forensic Sci Int. 2005;150:165-73. https://doi.org/10.1016/j.forsciint.2005. 02.028 .

Déglon J, Leuthold LA, Thomas A. Potential missing steps for a wide use of dried matrix spots in biomedical analysis. Bioanalysis. 2015;7:2375-82. https://doi.org/10.4155/bio.15.166.

Dobri SCD, Moslehi AH, Davies TC. Are oral fluid testing devices effective for the roadside detection of recent cannabis use? A systematic review. Public Health. 2019;171:57-65. https://doi.org/10.1016/j.puhe.2019.03.006.

DPX Technologies INTip ${ }^{\text {TM }}$ Solid Phase Extraction - Dispersive Pipette XTRaction Product Guide. https://dpxtechnologies.com/wp-content/uploads/ 2020/02/INTip-SPE-Guide_web2.pdf. Accessed 22 Feb 2021

Drummer $\mathrm{OH}$. Introduction and review of collection techniques and applications of drug testing of oral fluid. Ther Drug Monit. 2008;30:203-6. https:// doi.org/10.1097/FTD.0b013e3181679015.

Fink DS, Stohl M, Sarvet AL, et al. Medical marijuana laws and driving under the influence of marijuana and alcohol. Addiction. 2020:0-3. https://doi.org/ 10.1111/add.15031.

Gallagher R. Methadone: An effective, safe drug of first choice for pain management in frail older adults. Pain Med. 2009;10:319-26. https://doi.org/ 10.1111/j.1526-4637.2008.00551.x.

Gorziza R, Cox J, Pereira Limberger R, Arroyo-Mora LE. Extraction of dried ora fluid spots (DOFS) for the identification of drugs of abuse using liquid chromatography tandem mass spectrometry (LC-MS/MS). Forensic Chem. 2020;19: 100254. https://doi.org/10.1016/j.forc.2020.100254.

Hannon WH, Therrell BL. Overview of the History and Applications of Dried Blood Samples. In: Dried Blood Spots. Hoboken: Wiley; 2014. p. 1-15.

Huestis MA. Human Cannabinoid Pharmacokinetics Chem Biodivers. 2007:4:1770-804. https://doi.org/10.1002/cbdv.200790152.

Huestis MA, Cone EJ. Relationship of $\triangle 9$-tetrahydrocannabinol concentrations in oral fluid and plasma after controlled administration of smoked cannabis. J Anal Toxicol. 2004;28:394-9. https://doi.org/10.1093/jat/28.6.394.

Jacques ALB, dos Santos MK, Limberger RP. Development and Validation of a Method Using Dried Oral Fluid Spot to Determine Drugs of Abuse. J Forensic Sci. 2019;64:1906-12. https://doi.org/10.1111/1556-4029.14112.

Kyriakou C, Marchei E, Scaravelli G, et al. Identification and quantification of psychoactive drugs in whole blood using dried blood spot (DBS) by ultra-performance liquid chromatography tandem mass spectrometry. J Pharm Biomed Anal. 2016;128:53-60. https://doi.org/10.1016/j.jpba.2016. 05.011.

Langel K, Engblom C, Pehrsson A, et al. Drug testing in oral fluid - Evaluation of sample collection devices. J Anal Toxicol. 2008;32:393-401. https://doi. org/10.1093/jat/32.6.393.

Lee D, Huestis MA. Current knowledge on cannabinoids in oral fluid. Drug Test Anal. 2014;6:88-111. https://doi.org/10.1002/dta.1514.

Matuszewski BK, Constanzer ML, Chavez-Eng CM. Strategies for the assessment of matrix effect in quantitative bioanalytical methods based on HPLC-MS/MS. Anal Chem. 2003;75:3019-30. https://doi.org/10.1021/ ac020361s.

Mercolini L, Mandrioli R, Sorella V, et al. Dried blood spots: Liquid chromatography-mass spectrometry analysis of $\Delta 9$-tetrahydrocannabinol and its main metabolites. J Chromatogr A. 2013;1271:33-40. https://doi.org/10.1016/j. chroma.2012.11.030.

Michely JA, Meyer MR, Maurer HH. Dried urine spots - A novel sampling technique for comprehensive LC-MSn drug screening. Anal Chim Acta. 2017;982:112-21. https://doi.org/10.1016/j.aca.2017.05.033. 
Milman G, Schwope DM, Gorelick DA, Huestis MA. Cannabinoids and metabolites in expectorated oral fluid following controlled smoked cannabis. Clin Chim Acta. 2012;413:765-70. https://doi.org/10.1016/j.cca.2012.01.011.

Molnar A, Lewis J, Fu S. Recovery of spiked $\Delta$ 9-tetrahydrocannabinol in oral fluid from polypropylene containers. Forensic Sci Int. 2013;227:69-73. https://doi.org/10.1016/j.forsciint.2012.11.006.

Numako M, Takayama T, Noge I, et al. Dried Saliva Spot (DSS) as a Convenient and Reliable Sampling for Bioanalysis: An Application for the Diagnosis of Diabetes Mellitus. Anal Chem. 2016;88:635-9. https://doi.org/10.1021/acs. analchem.5b04059.

Pablo A, Breaud AR, Clarke W. Automated analysis of dried urine spot (DUS) samples for toxicology screening. Clin Biochem. 2020;75:70-7. https://doi. org/10.1016/j.clinbiochem.2019.10.009.

Pisanti S, Malfitano AM, Ciaglia E, et al. Cannabidiol: State of the art and new challenges for therapeutic applications. Pharmacol Ther. 2017;175:13350. https://doi.org/10.1016/j.pharmthera.2017.02.041.

Protti M, Rudge J, Sberna AE, et al. Dried haematic microsamples and LC-MS/ MS for the analysis of natural and synthetic cannabinoids. J Chromatogr B Anal Technol Biomed Life Sci. 2017;1044-1045:77-86. https://doi.org/10. 1016/j.jchromb.2016.12.038.

Ramanathan S, Parthasarathy S, Murugaiyah V, et al. Understanding the physicochemical properties of mitragynine, a principal alkaloid of Mitragyna speciosa, for preclinical evaluation. Molecules. 2015;20:4915-27. https:// doi.org/10.3390/molecules20034915.

Resano M, Belarra MA, García-Ruiz E, et al. Dried matrix spots and clinical elemental analysis. Current status, difficulties, and opportunities. TrAC Trends Anal Chem. 2018;99:75-87. https://doi.org/10.1016/j.trac.2017.12. 004.

Ribeiro A, Prata M, Vaz C, et al. Determination of methadone and EDDP in oral fluid using the dried saliva spots sampling approach and gas chromatography-tandem mass spectrometry. Anal Bioanal Chem. 2019;411:2177-87. https://doi.org/10.1007/s00216-019-01654-z.

Russo E, Guy GW. A tale of two cannabinoids: The therapeutic rationale for combining tetrahydrocannabinol and cannabidiol. Med Hypotheses. 2006;66:234-46. https://doi.org/10.1016/j.mehy.2005.08.026.

Sadler Simões S, CastañeraAjenjo A, Dias MJ. Dried blood spots combined to an UPLC-MS/MS method for the simultaneous determination of drugs of abuse in forensic toxicology. J Pharm Biomed Anal. 2018;147:634-44. https://doi.org/10.1016/j.jpba.2017.02.046.
SAMHSA. Mandatory Guidelines for Federal Workplace Drug Testing Programs. In: US Fed. Regist. 2019https://www.samhsa.gov/sites/default/files/progr ams_campaigns/division_workplace_programs/final-mg-oral-fluid.pdf. Accessed 15 Feb 2021

Scheidweiler KB, Newmeyer MN, Barnes AJ, Huestis MA. Quantification of cannabinoids and their free and glucuronide metabolites in whole blood by disposable pipette extraction and liquid chromatography-tandem mass spectrometry. J Chromatogr A. 2016;1453:34-42. https://doi.org/10. 1016/j.chroma.2016.05.024

Schulze H, Schumacher M, Urmeew R, et al. Driving Under the Influence of Drugs, Alcohol and Medicines in Europe-findings from the DRUID project. 2012; 1-58

Seymour C, Shaner RL, Feyereisen MC, et al. Determination of fentanyl analog exposure using dried blood spots with LC-MS-MS. J Anal Toxicol. 2019;43:266-76. https://doi.org/10.1093/jat/bky096.

Stoykova S, Kanev K, Pantcheva I, Atanasov V. Isolation and Characterization of Drugs of Abuse in Oral Fluid by a Novel Preconcentration Protocol. Anal Lett. 2016:49:2822-32. https://doi.org/10.1080/00032719.2016.1155594.

Thomas A, Geyer H, Schänzer W, et al. Sensitive determination of prohibited drugs in dried blood spots (DBS) for doping controls by means of a benchtop quadrupole/Orbitrap mass spectrometer. Anal Bioanal Chem. 2012;403:1279-89. https://doi.org/10.1007/s00216-011-5655-2.

Walsh JM, Verstraete AG, Huestis MA, Mørland J. Guidelines for research on drugged driving. Addiction. 2008;103:1258-68. https://doi.org/10.1111/j. 1360-0443.2008.02277x.

White CM. A Review of Human Studies Assessing Cannabidiol's (CBD) Therapeutic Actions and Potential. J Clin Pharmacol. 2019;59:923-34. https:// doi.org/10.1002/jcph.1387.

Zakaria R, Allen KR, Koplin JJ, Roche P, Greaves RF (2016). Advantages and challenges of dried blood spot analysis by mass spectrometry across the total testing process. J Int Fed Clin Chem Lab Med 27(4):288-317.

\section{Publisher's Note}

Springer Nature remains neutral with regard to jurisdictional claims in published maps and institutional affiliations.
Ready to submit your research? Choose BMC and benefit from:

- fast, convenient online submission

- thorough peer review by experienced researchers in your field

- rapid publication on acceptance

- support for research data, including large and complex data types

- gold Open Access which fosters wider collaboration and increased citations

- maximum visibility for your research: over 100M website views per year

At BMC, research is always in progress.

Learn more biomedcentral.com/submissions 